\title{
EFETIVIDADE DO HEDGE DE SOJA EM GRÃO BRASILEIRA COM CONTRATOS FUTUROS DE DIFERENTES VENCIMENTOS NA CHICAGO BOARD OF TRADE ${ }^{1}$
}

\author{
Anamaria Gaudencio Martins ${ }^{2}$ \\ Danilo R. D. Aguiar
}

Resumo - O objetivo geral deste artigo foi examinar a proteção oferecida pelos contratos futuros da CBOT (Chicago Board of Trade), nos seus diferentes vencimentos, aos hedgers brasileiros de soja em grão. O modelo empírico consistiu em calcular a efetividade do hedge entre diversas regiões do Brasil e os contratos futuros de soja em grão, da CBOT. Os resultados mostraram que os contratos com vencimento no segundo semestre são mais efetivos, particularmente os que têm vencimento em julho e agosto. Além disso, quebras da safra norte-americana podem fazer com que contratos, mesmo com vencimentos em novembro e janeiro, se tornem altamente efetivos, em decorrência da maior procura pela mercadoria brasileira. Os resultados mostraram ainda que a efetividade é maior naquelas regiões próximas a portos de exportação, como é o caso dos municípios de Cândido Mota (SP), Campo Mourão (PR) e Ponta Grossa (PR).

Palavras-chave: Efetividade, hedge, soja em grão.

\section{Introdução}

A importância do complexo soja para o Brasil pode ser dimensionada tanto pelo impressionante crescimento da produção desta leguminosa quanto pela arrecadação de divisas com as exportações de soja em grão e derivados (óleo e farelo de soja). Os produtos do complexo soja, no

\footnotetext{
Pesquisa financiada pelo CNPq, ao qual os autores são gratos.

Recebido em 20/09/2004 Aceito em 04/11/2004

2 Economista formada pela Universidade Federal de Viçosa. Ex-bolsista de CNPq.

${ }^{3}$ Professor Adjunto IV do Departamento de Economia Rural, da Universidade Federal de Viçosa, e pesquisador do CNPq. E-mail:danilo@ufv.br
} 
conjunto, têm sido os principais representantes do agronegócio nas exportações brasileiras, visto que sua participação atingiu $9,1 \%$ das exportações globais do país em 2001, o que coloca este complexo como o maior setor exportador do Brasil.

De acordo com a Agrianual (2003), embora o país esteja se mantendo como segundo maior produtor mundial, a taxa de crescimento da produção brasileira, entre 1995/96 e 2001/02, atingiu 80\%, enquanto a dos Estados Unidos, o maior produtor, não passou de 33\%. Outra característica importante da produção do Brasil e da norte-americana é que elas são alternadas ao longo do ano. Enquanto a safra do Hemisfério Sul ocorre no primeiro semestre, a do Hemisfério Norte se dá no segundo semestre. Uma provável conseqüência de tal comportamento é que os preços internacionais tenderiam a ser mais influenciados pelas ofertas do Brasil e da Argentina, no primeiro semestre, e pela oferta norte-americana, no segundo.

Entretanto, por trás desse desempenho, os produtores brasileiros de soja têm se defrontado com situações mais desvantajosas do que seus principais concorrentes, os norte-americanos. Entre as dificuldades dos produtores brasileiros está a carência de mecanismos para lidar com a elevada volatilidade de preços que caracteriza o setor.

Estimativas feitas por Aguiar (2004) mostram que, entre os principais produtos agropecuários brasileiros, a volatilidade de preço da soja só não é maior do que a do café. Segundo este autor, a volatilidade média anual do preço da soja, no Brasil, atingiu 17,39\%, no período de julho de 2000 a outubro de 2002. Essa volatilidade decorre tanto de choques de oferta dos vários países produtores, quanto de mudanças na demanda de soja e derivados. Especificamente, os preços variam devido à difusão de informações incertas a respeito do nível de produção dos principais exportadores, variações no nível de consumo interno, perdas de produção ocasionadas por efeitos climáticos, disponibilidade de produtos substitutos, dentre outros fatores. Com isso, o uso de estratégias para reduzir a volatilidade de preço é de grande importância para os agentes que atuam na produção e comercialização de soja e derivados. 
Uma das principais estratégias para reduzir a volatilidade de preços, comumente usada por produtores, cooperativas, processadores e traders norte-americanos, é o hedge com contratos futuros. Por meio dessa estratégia, os produtores e cooperativas vendem contratos futuros para se defenderem de eventuais quedas de preços, ao passo que os agentes que buscam proteção contra aumento de preços compram contratos futuros. Os preços das commodities comercializadas nas bolsas de mercadorias são determinados, basicamente, pelas expectativas dos agentes que atuam no mercado. As informações sobre o aumento ou quebra de safra são os principais fatores que elevam a volatilidade de preços das mercadorias no mercado futuro (atrativo para especuladores).

Para que a utilização do mercado futuro, como forma de gerenciamento de risco, seja atrativa aos agentes, é necessário que haja liquidez nas operações de compra e venda de contratos futuros, de forma que os agentes possam entrar e sair do mercado com mais facilidade. Esse requisito é essencial para um bom gerenciamento de riscos, dado que é mínima a porcentagem de contratos liquidados pela entrega física do produto.

Entretanto, para os agentes do complexo soja brasileiro, a adoção de estratégias de hedge é problemática porque o contrato futuro de soja em grão, da Bolsa de Mercadorias e Futuros (BM\&F), tem apresentado baixíssimo volume de comércio, chegando mesmo a ficar quase sem negociação em 2001 e 2002. No final de 2002, uma versão reformulada do contrato de soja foi lançada pela BM\&F, mas os resultados não têm sido os esperados. Como o volume de comércio é incipiente, o mercado tende a ser ineficiente, e os investidores correm o risco de não fecharem suas posições por diferença, a um preço justo, no momento que desejarem.

Em 2003 foram negociados, no total, 2.917 contratos na BM\&F (BM\&F, 2004), valor insignificante se comparado aos contratos negociados na Chicago Board of Trade (CBOT), que totalizaram um número superior a 17 milhões de contratos, no mesmo ano (CBOT, 2004). A alta liquidez dos contratos na CBOT é tida como o principal fator que leva os grandes agentes do mercado de soja a atuarem nessa bolsa. 
Entretanto, trabalhos como os de Lazzarini (1997) e Silva et al. (2003) têm sugerido que os contratos futuros da CBOT proporcionam pouca proteção contra risco de preços para os hedgers brasileiros. Silva et al. (2003), em particular, ao analisarem a proteção oferecida pelos contratos da CBOT para 13 regiões brasileiras, verificaram que os níveis de proteção proporcionados pelo contrato de soja em grão desta bolsa, em relação a quem não fez hedge, variaram de $17 \%$ a $53 \%$, bastante inferiores aos encontrados por aqueles autores para os contratos da BM\&F.

Embora os trabalhos de Lazzarini (1997) e Silva et al. (2003) sugiram que contratos da CBOT proporcionem pouca proteção aos hedgers brasileiros, algumas limitações dos métodos adotados por esses autores e a recente mudança no desenho do contrato da CBOT podem indicar que a generalização dos resultados por eles encontrados é inapropriada. Em primeiro lugar, os trabalhos mencionados formaram a série de preços futuros por meio do procedimento conhecido como "primeiro vencimento", ou seja, formaram uma série única de preços futuros composta pelas cotações do próximo contrato a vencer. Dessa forma, esses trabalhos não puderam verificar se, em algumas épocas do ano, a proteção oferecida pelo contrato da CBOT era maior do que em outras épocas. Essa possibilidade é bastante plausível, uma vez que a safra brasileira se concentra num período diferente da dos Estados Unidos, conforme esclarecido anteriormente.

Outro aspecto a ser considerado é que o ponto de entrega do contrato futuro da CBOT foi modificado no início de 2001, transferindo-se do interior do Estado de Illinois para um porto no rio Illinois. Essa alteração contratual visou dar maior transparência à formação da cotação da CBOT, o que pode ter resultado em aumento da correlação entre as cotações desta bolsa e os preços internacionais, incluindo os do Brasil. Como o estudo de Silva et al. (2003) envolveu dados até 2000 e o de Lazzarini (1997) cobriu período ainda anterior, os resultados obtidos por esses autores podem ter subestimado a proteção, proporcionada pelos contratos da CBOT, aos hedgers brasileiros, após a mudança contratual promovida pela CBOT. 
Nesse contexto, o objetivo geral deste trabalho foi examinar a proteção, oferecida pelos contratos futuros da CBOT, nos seus diferentes vencimentos, aos hedgers brasileiros que operam com soja em grão. Especificamente, pretendeu-se determinar em quais épocas do ano a operação de hedge proporciona maior proteção contra o risco de preço e em quais regiões do país a operação de hedge possibilita maior proteção.

Este trabalho, por adotar um método diferente do utilizado em estudos anteriores, para formar as séries de preços futuros (contrato a contrato, em vez de primeiro vencimento), permitirá o teste de duas hipóteses. A primeira é que os contratos da CBOT, com vencimento no primeiro semestre, proporcionariam maior redução do risco de preço para os hedgers brasileiros, uma vez que a safra brasileira afetaria mais as cotações neste período. A segunda é que as regiões mais próximas a portos de exportação teriam maior proteção por meio do hedge em relação a regiões mais distantes, devido ao menor custo de transporte, o que tornaria o preço interno mais correlacionado com os preços internacionais e com as cotações dos contratos da CBOT.

\section{Referencial teórico}

Admita que o hedger tenha o objetivo de maximizar sua riqueza e que ele também seja um investidor avesso ao risco, com um portfólio (carteira) composto por dois ativos: uma posição no mercado físico e uma posição no mercado futuro. Considerando um hedge de venda entre o período de estabelecimento (1) e de encerramento (2), Blank et al. (1991) e Stoll e Whaley (1993) mostraram que a receita de um hedger pode ser dada por:

$$
R_{h}=V\left(p_{2}^{\prime}-p_{1}\right)+F\left(f_{1}-f_{2}^{\prime}\right) \text { ou } R_{h}=V\left(p_{2}^{\prime}-p_{1}\right)+F\left(f_{2}^{\prime}-f_{1}\right),
$$

em que $R_{h}$ é receita bruta num portfólio com posições nos mercados futuros e a vista; $V$, tamanho da posição no mercado a vista; $p_{2}^{\prime}-p_{1}$, 
diferença entre os preços no mercado a vista, nos períodos 2 e 1; $F$, tamanho da posição no mercado futuro; e $f_{2}^{\prime}-f_{1}$, diferença entre os preços no mercado futuro, nos períodos 2 e 1 .

Dividindo a expressão (1) por V, obtém-se a receita por unidade de produto:

$$
\frac{R_{h}}{V}=\left(p_{2}^{\prime}-p_{1}\right)-h\left(f_{2}^{\prime}-f_{1}\right),
$$

sendo $h$ a razão de hedge $\left(\frac{F}{V}\right)$, que mostra o tamanho da posição no mercado futuro em relação à posição no mercado a vista. Por exemplo, $h=0,5$ significa que, para cada 1.000 sacas estocadas por um hedger de venda, 500 sacas foram vendidas, na forma de contratos futuros, no mercado futuro.

Ao aplicar a propriedade da variância de uma soma à equação (2), obtém-se a variância da receita por unidade do produto:

$\sigma_{h}^{2}=\sigma_{p}^{2}-2 h \sigma_{p f}+h^{2} \sigma_{f}^{2}$

em que $\sigma_{h}^{2}$ é variância da receita por unidade do produto; $\sigma_{p}^{2}$, variância da mudança do preço no mercado físico; $\sigma_{p f}$, covariância entre as mudanças do preço no mercado físico e do preço futuro; e $\sigma_{f}^{2}$, variância da mudança do preço futuro.

Pela condição de primeira ordem para minimização da variância da receita, chega-se à razão ótima do hedge ( $\left.\mathrm{h}^{*}\right)$, derivando-se a variância da receita com respeito a $\mathbf{h}$ e igualando-se o resultado a zero: 


$$
\begin{aligned}
& \frac{\partial \sigma_{h}^{2}}{\partial h}=-2 \sigma_{p f}+2 h \sigma_{f}^{2}=0, \\
& \sigma_{p f}=h^{*} \sigma_{f}^{2}, \\
& h^{*}=\frac{\sigma_{p f}}{\sigma_{f}^{2}}
\end{aligned}
$$

Dessa forma, a razão ótima do hedge, $\mathbf{h}$, ou seja, a razão de hedge que permite minimizar a variância da receita do hedger, depende diretamente da covariância entre as mudanças nos preços futuro e a vista, e inversamente da variância do preço futuro.

A partir disso, é possível calcular a efetividade do hedge, que é a proporção da variância da receita que pode ser eliminada por meio da adoção de um portfólio com a razão ótima do hedge. Matematicamente, a efetividade do hedge pode ser representada por:

$$
e=\frac{\operatorname{Var}(p)-\operatorname{Var}\left(h^{*}\right)}{\operatorname{Var}(p)}=1-\frac{\operatorname{Var}\left(h^{*}\right)}{\operatorname{Var}(p)}
$$

sendo $\operatorname{Var}\left(h^{*}\right)$ a variância da receita num portfólio com hedge à razão ótima, e $\operatorname{Var}(p)$, variância da receita num portfólio sem hedge.

Analisando a equação (5), nota-se que se o hedge eliminasse totalmente o risco $\operatorname{Var}\left(h^{*}\right)=0$, a efetividade seria igual a um. No outro extremo, caso as variâncias da receita com e sem hedge fossem iguais, a efetividade seria igual a zero. Portanto, a efetividade do hedge variaria 
de zero a um, ou de zero a cem, caso se optasse por expressá-la em percentagem.

Como Var(p) depende unicamente do comportamento dos preços a vista, a variância da receita em um portfólio sem hedge é a própria variância da mudança do preço no mercado físico. Por outro lado, $\operatorname{Var}\left(\mathrm{h}^{*}\right)$ pode ser obtida pela substituição de (4) em (3):

$$
\operatorname{Var}\left(h^{*}\right)=\sigma_{p}^{2}-2\left(\frac{\sigma_{p f}}{\sigma_{f}^{2}}\right) \cdot \sigma_{p f}+\left(\frac{\sigma_{p f}}{\sigma_{f}^{2}}\right)^{2} \cdot \sigma_{f}^{2}
$$

Simplificando, tem-se:

$$
\operatorname{Var}\left(h^{*}\right)=\sigma_{p}^{2}-\left(\frac{\sigma_{p f}}{\sigma_{f}}\right)^{2} .
$$

Para se chegar a uma fórmula que envolve a correlação, multiplica-se e divide-se o último elemento da equação acima por $\sigma_{\mathrm{p}}^{2}$ :

$$
\operatorname{Var}\left(h^{*}\right)=\sigma_{p}^{2}-\left(\frac{\sigma_{p f}}{\sigma_{f}}\right)^{2} \cdot \frac{\sigma_{p}^{2}}{\sigma_{p}^{2}}=\sigma_{p}^{2}-\left(\frac{\sigma_{p f}}{\sigma_{f} \sigma_{p}}\right)^{2} \cdot \sigma_{p}^{2}=\sigma_{p}^{2}\left(1-\rho^{2}\right) .
$$

Portanto, substituindo $\sigma_{p}^{2}$ e (6) em (5), tem-se

$$
e=1-\frac{\sigma_{p}^{2}\left(1-\rho^{2}\right)}{\sigma_{p}^{2}}=\rho^{2}
$$

Desse modo, a equação (7) mostra que a efetividade do hedge, quando se utiliza razão ótima de hedge, é o quadrado da correlação linear entre as mudanças dos preços a vista e futuro. Como o quadrado da correlação linear entre as mudanças dos preços a vista e futuro varia de zero a 
um, a efetividade de hedge, quando se utiliza a razão de hedge ótima, também varia de zero a um $(0<\mathrm{e}<1)$, como mencionado anteriormente. A efetividade de hedge será máxima quando as mudanças dos preços a vista e futuro forem perfeitamente correlacionadas, diminuindo à medida que a correlação entre as mudanças dos preços a vista e futuro diminui. Assim, pode-se concluir que quanto maior a correspondência entre o produto comercializado no mercado a vista e o produto especificado nos contratos futuros, maior será a correlação entre as mudanças nos preços a vista e futuro e, conseqüentemente, maior tenderá a ser a efetividade de hedge, quando se utiliza a razão de hedge ótima (Aguiar, 1999).

\section{Metodologia}

\subsection{Dados}

Os dados básicos utilizados no cálculo da efetividade do hedge são provenientes de séries temporais diárias de preços da soja a vista $(\mathrm{R} \$ /$ saca de $60 \mathrm{~kg}$ ), no mercado interno (preço pago ao produtor), e dos preços de fechamento dos contratos futuros de soja em grão, na Chicago Board of Trade (cents de US\$/bushel), no período de 10/09/2000 a 10/03/2004. O início do período foi determinado para possibilitar o cálculo da efetividade para contratos a partir de janeiro de 2001.

As regiões envolvidas correspondem às grandes microrregiões produtoras de soja dos principais estados produtores, como Bahia (Barreiras), Paraná (Cascavel, Ponta Grossa e Campo Mourão), Mato Grosso (Sorriso, Cuiabá e Rondonópolis), Rio Grande do Sul (Passo Fundo), Minas Gerais (Uberlândia), Goiás (Rio Verde), Mato Grosso do Sul (Dourados), São Paulo (Cândido Mota e Orlândia) e Maranhão (Balsas). 
Todas as séries de preços foram obtidas no banco de dados da Consultoria \& Pesquisa, FNP.

\subsection{Procedimentos empíricos}

Como destacado anteriormente, uma forma de estimar a efetividade do hedge é por meio do cálculo da correlação entre os preços a vista e futuro, elevando-se o resultado ao quadrado. Esse procedimento já havia sido adotado anteriormente por Nogueira (2002), para o mercado de café arábica.

Dessa forma, a efetividade do hedge é determinada pelo cálculo do quadrado da correlação linear entre as variáveis preço a vista e preço futuro, conforme a equação (8):

$$
e=\rho^{2}
$$

Na estimação das efetividades, o procedimento utilizado na separação dos dados é o de agrupá-los por diferentes vencimentos. As séries de cada região e da CBOT foram separadas em períodos de quatro meses antes do vencimento de cada contrato. Para um contrato com vencimento em janeiro, por exemplo, toma-se o período de 10 de setembro a 10 de janeiro ${ }^{4}$.

As séries diárias dos preços futuros foram transformadas para US\$/ saca de $60 \mathrm{~kg}$, uma vez que os preços a vista estavam nesta unidade. Posteriormente, todas as séries foram organizadas em dados semanais. A opção por trabalhar com preços semanais, e não diários, decorre do argumento, apresentado por Stoll e Whaley (1993), de que as freqüências de comercialização nos mercados físicos e futuros não são as mesmas, o que faz com que as mudanças de preços a vista e futuro não

\footnotetext{
${ }^{4}$ O último dia de negociação é o anterior ao dia 15 do calendário do mês do vencimento do contrato. Entretanto, a escolha de não se trabalhar com as últimas cotações a futuro, antes do vencimento, deve-se ao fato de as últimas cotações refletirem maior instabilidade do mercado, uma vez que os preços devem convergir.
} 
reflitam a mesma série de informações de mercado. Assim, este problema afeta os resultados de estimações com dados diários, já que a freqüência de comercialização física da soja é, na maioria das vezes, inferior à dos contratos futuros.

A opção por trabalhar com quatro meses antes de cada vencimento, a qual tem sido praxe em outros estudos, deve-se ao fato de o uso de períodos de seis meses incluir momentos de baixa liquidez nas observações mais distantes do vencimento. Por outro lado, caso se utilizasse período menor que quatro meses, ter-se-ia um número de observações muito pequeno.

A observação utilizada para representar o preço de cada semana foi o preço da quarta-feira, por ser este o dia de maior volume de comércio na CBOT. Nas semanas em que não houve pregão na quarta-feira, tomouse o dia imediatamente posterior ou anterior.

De posse das séries semanais (geralmente, 18 observações), calculouse a correlação entre o preço a vista de cada região e a cotação futura do contrato de soja em grão na CBOT, para cada vencimento, sendo os vencimentos da CBOT, para o contrato de soja em grão, nos meses de janeiro, março, maio, julho, agosto, setembro e novembro.

A avaliação da efetividade do hedge envolve duas dimensões. A primeira diz respeito aos diferentes vencimentos dos contratos futuros e a segunda, às diferentes microrregiões estudadas. Além disso, a cada vencimento há uma observação para cada ano. Desse modo, inicialmente, foram analisados os resultados de cada vencimento, anualmente, em cada uma das 16 regiões. Em seguida, a análise foi feita com as médias de cada contrato.

Para as regiões de Balsas (MA), Cândido Mota (SP) e Sorriso (MT), a série de preços, da fonte de dados, não abrangeu todo o período. Dessa forma, não foi possível o cálculo da efetividade dos contratos com vencimento em julho, agosto, setembro e novembro do ano de 2000 , nessas regiões. 


\section{Resultados e discussão}

De maneira geral, a efetividade do hedge variou muito de uma região para outra, de um ano para outro e de um vencimento para outro (o que era esperado, em razão de as safras brasileira e americana ocorrerem em semestres diferentes do ano).

Os Quadros 1 e 2 apresentam os valores da efetividade do hedge de soja em grão com contratos futuros da CBOT, para vencimentos no primeiro semestre do ano (janeiro, março e maio, respectivamente).

Ao contrário do que se admitiu na primeira hipótese desta pesquisa, os valores da efetividade do hedge foram baixíssimos para esses vencimentos, chegando a ser inexpressivos, em alguns anos, nos contratos com vencimento em março ${ }^{5}$. Note-se que, para o contrato com vencimento em janeiro, as estimativas de efetividade do hedge, em 2004, foram expressivamente superiores às dos demais anos. Uma possível explicação para a maior efetividade em 2004 decorre da quebra de safra dos Estados Unidos em 2003. Como a safra norte-americana, neste ano, foi a menor desde 1996, os preços da soja em grão brasileira mostraramse mais correlacionados com as cotações da CBOT. Observa-se ainda que, em algumas regiões, principalmente as pertencentes aos estados do Mato Grosso e Mato Grosso do Sul, a proteção dada aos sojicultores é muito inferior à das demais regiões, principalmente às pertencentes aos estados de São Paulo, Paraná e Minas Gerais. Em Dourados (MS), não houve correlação entre o preço a vista da região e a cotação futura da CBOT, em 2002.

Para os contratos com vencimentos em março (Quadro 2), as estimativas das efetividades do hedge foram ainda menores do que as encontradas nos contratos com vencimentos em janeiro. Em 2001, as efetividades do hedge foram elevadas, comportamento que não teve continuidade nos anos posteriores, em que todos os valores foram prati-

\footnotetext{
${ }_{5}^{5}$ Os piores resultados para os contratos de março ocorreram nos anos de 2002 e 2003.
} 
camente inexpressivos. Pode-se afirmar, diante desses resultados, que o risco de quem faz hedge com os contratos futuros da CBOT, com vencimento em março, é praticamente o mesmo de quem não o faz.

No geral, o comportamento das efetividades do hedge, com vencimento em maio (Quadro 2), foi similar ao de março: valores altos em 2001, que estariam relacionados com a quebra de safra norte-americana em 2000, e baixos nos demais anos. Dessa forma, os contratos com vencimento em março e maio seriam, na maioria das vezes, não-efetivos aos hedgers brasileiros. Entretanto, em alguns anos, acontecimentos como a quebra da safra norte-americana poderiam aumentar a correlação entre os preços a vista no mercado brasileiro e futuro na CBOT, devido à maior procura pelo produto brasileiro, em decorrência da escassez do produto norte-americano. Esse comportamento pode ser visualizado na coluna correspondente ao ano de 2001.

Devido ao alto grau de variação dos valores de efetividade do hedge estimados, é difícil a determinação de quais regiões trariam maior proteção aos hedgers de soja. Todavia, nos contratos com vencimento no primeiro semestre do ano, as regiões de Campo Mourão (PR), Cascavel (PR), Maringá (PR), Ponta Grossa (PR) e Orlândia (SP) apresentaram, na maioria das vezes, valores de efetividade do hedge superiores aos das demais regiões analisadas.

Em suma, as estratégias de hedge, quando se utilizam contratos futuros da CBOT com vencimentos no primeiro semestre, foram pouco interessantes para os produtores brasileiros.

No início do segundo semestre (Quadro 3), as operações de hedge com contratos de soja em grão passaram a ser mais efetivas com os contratos de soja da CBOT. Em Ponta Grossa (PR), o contrato futuro, com vencimento em agosto, chegou a ter $97,4 \%$ de efetividade do hedge, valor que significa que o risco do hedger seria igual a $2,6 \%$ do de quem não o havia feito. 
É interessante ressaltar que, além de apresentarem melhores resultados, os contratos com vencimento em julho e agosto apresentaram menor variabilidade dos resultados de um ano a outro, se comparados aos contratos com vencimento no primeiro semestre. Menor variabilidade aumenta a confiabilidade dos resultados. No entanto, em algumas regiões, como é o caso de Barreiras (BA) e os municípios do Mato Grosso, a efetividade do hedge foi bastante inferior no ano de 2003, ocorrendo o mesmo em Rio Verde (GO), Orlândia (SP) e Uberlândia (MG), em 2001, no contrato com vencimento em julho. Uma possível explicação para esses casos extremos é que, em alguns anos, a maior parte da produção havia sido vendida com bastante antecedência em algumas regiões, o que reduziu drasticamente a correlação entre os preços a vista nestas regiões e as cotações da CBOT.

Para os vencimentos de setembro e novembro (Quadro 4), as efetividades do hedge voltaram a diminuir, mas ainda são, na maioria das vezes, superiores às referentes ao primeiro semestre. Nas estimativas de setembro, as microrregiões de Mato Grosso apresentaram valores de efetividade do hedge superiores aos das microrregiões de São Paulo e Paraná, no ano de 2002. Porém, no ano de 2003, foi inexpressiva a proteção oferecida aos agentes negociadores de soja em grão matogrossense. Esse fato se assemelha ao que havia ocorrido com os contratos de julho e agosto, o que poderia ser decorrente da antecipação das vendas por parte dos produtores. Além disso, como no primeiro semestre de 2003 havia expectativa de uma grande safra norte-americana, isso pode ter facilitado a redução da correlação entre os preços a vista, de algumas regiões, e as cotações futuras, da CBOT.

As estimativas da efetividade do hedge para o vencimento em novembro foram, em 2001 e 2002, inferiores às referentes ao vencimento anterior. Em 2003, a efetividade do hedge, com o contrato futuro de novembro, foi substancialmente maior que com os demais contratos, variando de 90,8\% (Balsas) a 98,1\% (Rondonópolis). Esse bom desempenho foi refletido, também, nos valores referentes ao vencimento de janeiro de 2004 (Quadro 1). Uma possível explicação para este fato, já discutida 
anteriormente, decorre da quebra da safra de 2003 nos Estados Unidos, o que aumentou a procura pelo produto em outras regiões produtoras e, portanto, a correlação entre os preços a vista dessas regiões (entre as quais o Brasil) e os preços futuros da CBOT.

Por outro lado, os resultados podem ser agregados para refletir as médias por região, totais e por vencimento (Quadro 5). Os resultados sugerem que os agentes negociadores de soja possuem, nos contratos de soja em grão da CBOT com vencimentos no primeiro semestre do ano, menor proteção ao risco de preço quando comparados aos do segundo semestre. Em média, a efetividade dos contratos do primeiro semestre foi de 0,35 , enquanto a do segundo semestre, de 0,6. Entretanto, é de extrema importância que os hedgers estejam atentos às informações disponíveis no momento da tomada de decisão, porque, apesar de neste trabalho ter se constatado que os contratos com vencimento no primeiro semestre são, em média, menos efetivos, a efetividade do hedge costuma mudar de ano para ano.

Os vencimentos que apresentaram maior efetividade de hedge, para a soja em grão brasileira, são, via de regra, julho e agosto. O que há de comum entre esses meses é que eles marcam o pico da entressafra americana. Assim, as cotações dos contratos futuros, com vencimento no segundo semestre, seriam mais influenciadas pela safra norte-americana e as do primeiro semestre, pelo volume de estoque de passagem ${ }^{6}$. No pico da entressafra, no entanto, a redução de estoques e a ausência do produto norte-americano aumentariam a procura pelo produto no hemisfério sul e, conseqüentemente, a correlação entre os preços a vista nas diversas regiões brasileiras e as cotações da CBOT.

Pela análise nas regiões, nota-se que os hedgers de Cândido Mota, Campo Mourão e Ponta Grossa teriam maior efetividade do que os das demais regiões. Além disso, as microrregiões de Mato Grosso (Sorriso, Rondonópolis e Cuiabá) apresentaram a menor efetividade de hedge, entre todas as microrregiões. É interessante observar que as regiões que

${ }_{6}^{6}$ Considera-se estoque de passagem aquele que passa de uma safra a outra. 
apresentaram estimativas da média da efetividade do hedge superiores a $50 \%$ são, exceto Dourados, próximas a portos de embarque de soja para exportação. $\mathrm{O}$ que a observação sugere é que, além de fatores como qualidade da soja, tempo de armazenagem etc, o fator custo de transporte assume, nesse caso, importância para aumentar a correlação entre o preço da soja em grão nas diversas regiões brasileiras e as cotações futuras.

Portanto, deve-se notar que as variações que ocorrem de um ano para outro podem estar associadas ao volume de estoque de passagem e ao tamanho das safras dos países, em especial dos Estados Unidos. Dessa forma, a quebra da safra norte-americana poderia aumentar a efetividade do hedge para os produtos brasileiros, mesmo nos contratos com vencimento em novembro e janeiro. Além disso, os resultados encontrados mostram valores, em média, bastante superiores aos obtidos por Silva et al. (2003) e Lazzarini (1997), o que pode decorrer do aumento da correlação dos preços após a mudança do contrato da CBOT ou, então, do fato de se utilizar outro método no cálculo da efetividade. Se, por um lado, o cálculo da efetividade por vencimento permitiu verificar as diferenças entre vencimentos, por outro, limitou a comparação com os resultados obtidos, em períodos anteriores, por outros autores, já que estes utilizaram o método do "primeiro vencimento".

\section{Conclusão}

O que as estimativas do hedge permitiram concluir é que as cotações dos contratos futuros, com vencimento no segundo semestre, seriam mais influenciadas pela safra norte-americana e as do primeiro semestre, pelo volume de estoque dessa commodity. No pico da entressafra norte-americana (março a julho), no entanto, a redução de estoques e a ausência do produto norte-americano aumentaram a procura pelo produto no hemisfério sul e, conseqüentemente, a correlação entre os preços a vista nas diversas regiões brasileiras e as cotações da CBOT. Entretanto, esse comportamento não se manteve em todos os anos. Aparentemente, 
nos anos em que houve grande procura pela soja brasileira no mercado internacional, em decorrência de queda da oferta norte-americana, a correlação entre os preços a vista, no mercado interno, e futuros, na CBOT, tendeu a aumentar, tornando as operações de hedge bastante efetivas para os agentes brasileiros.

Em relação às hipóteses propostas neste trabalho, não se rejeita a de que hedgers localizados mais próximos aos portos de embarque de soja teriam maior efetividade do hedge. Assim, hedgers localizados em áreas de fronteira, como o estado do Mato Grosso, seriam menos beneficiados pelo hedge com contratos da CBOT do que aqueles localizados na região Centro-Sul do país. Entretanto, a hipótese de que a efetividade do hedge seria maior no período de safra brasileira é rejeitada. Dessa forma, seria recomendável que os hedgers brasileiros utilizassem contratos futuros, de julho ou agosto, em suas operações de hedge.

\section{Referências bibliográficas}

AGRIANUAL. Anuário estatístico da agricultura brasileira. São Paulo: FNP Consultoria e Comércio, 2003.

AGUIAR,D.R.D, Agricultural Futures Contracts in Brazil: Evolution and Perspectives. In: Moura, A.D. \& Silva Junior, A.G. Competitividade do Agronegócio Brasileiro em Mercados Globalizados. Viçosa, 2004.

AGUIAR, D.R.D. Mercados Futuros Agropecuários. Viçosa: UFV, 1999.

BLANK,S.C.;CARTER,C.A; SCHMIESING,BH. Futures and options markets- trading in commodities and financials. Englewood cliffs: Prentice-Hall, Inc.;1991.410p.

BM\&F - BOLSA DE MERCADORIAS \& FUTUROS (http:// www.BM\&F.com.br) 2004. 


\section{CBOT - CHICAGO BOARD OF TRADE (http://www.cbot.com) 2004.}

LAZZARINI, S.G. Gerenciamento de riscos de preços no sistema agroindustrial brasileiro da soja. Revista de Economia e Sociologia Rural. Brasília: SOBER, vol. 35, nº 4, Out./Dez., 1997. p.41-64.

NOGUEIRA, F.T.P, Integração espacial e efetividade do hedge no mercado brasileiro de café arábica. São Paulo: Bolsa de Mercadorias \& Futuros, 2002.

SILVA, A.R.O., AGUIAR, D.R.D. e LIMA, J.E. Hedge com Contratos Futuros no Complexo Soja Brasileiro: BM\&F vs. CBOT. Revista de Economia e Sociologia Rural. Brasília: SOBER, vol. 41, nº 2, Abr./ Jun., 2003. (no prelo).

STOLL, H.R. e WHALEY,R.E, Hedging with futures contracts. Futures and Options-theory and applications. Cincinnati: South-Western Publishing Co., 1993. 413.p.

\footnotetext{
Abstract - The objective of this paper was to analyze the risk protection provided by the futures contracts traded at CBOT (Chicago Board of Trade) at different delivery months to Brazilian Soybean hedgers. The empirical approach adopted was the estimation of hedging effectiveness between every Brazilian production state and the CBOT futures contracts. The results showed that the contracts for delivery in the second semester are more effective, mainly those for delivery in July and August. Moreover, supply shocks in the U.S. can make even the contracts for delivery in November and January to be very effective because of stronger procurement for Brazilian soybeans. The results also show that hedging effectiveness is larger near export harbors, as they were the cases of Cândido Mota (SP), Campo Mourão (PR) and Ponta Grossa (PR).

Keywords: Effectiveness, hedge, soybeans.
} 
Quadro 1 - Efetividade para os contratos com vencimentos em janeiro

\begin{tabular}{lcccc}
\hline \multicolumn{1}{c}{ Região } & \multicolumn{3}{c}{ Anos } \\
& $\mathbf{2 0 0 1}$ & $\mathbf{2 0 0 2}$ & $\mathbf{2 0 0 3}$ & $\mathbf{2 0 0 4}$ \\
\hline Balsas - MA & 0,620 & 0,553 & 0,393 & 0,812 \\
Barreiras - BA & 0,445 & 0,006 & 0,502 & 0,573 \\
Campo Mourão - PR & 0,497 & 0,383 & 0,452 & 0,753 \\
Candido Mota - SP & 0,393 & 0,304 & 0,451 & 0,784 \\
Cascavel - PR & 0,437 & 0,382 & 0,455 & 0,753 \\
Chapecó - SC & 0,413 & 0,351 & 0,308 & 0,748 \\
Cuiabá - MT & 0,239 & 0,113 & 0,267 & 0,589 \\
Dourados - MS & 0,305 & 0,000 & 0,516 & 0,714 \\
Maringá - PR & 0,483 & 0,324 & 0,572 & 0,724 \\
Orlândia - SP & 0,436 & 0,440 & 0,354 & 0,841 \\
Passo Fundo - RS & 0,454 & 0,155 & 0,292 & 0,876 \\
Ponta Grossa - PR & 0,498 & 0,206 & 0,441 & 0,811 \\
Rio Verde- GO & 0,185 & 0,564 & 0,399 & 0,829 \\
Rondonópolis - MT & 0,259 & 0,008 & 0,207 & 0,615 \\
Sorriso - MT & 0,435 & 0,057 & 0,177 & 0,603 \\
Uberlândia - MG & 0,406 & 0,541 & 0,366 & 0,857 \\
\hline
\end{tabular}

Fonte: Resultados da pesquisa. 
Quadro 2-Efetividade para os contratos com vencimentos em março e maio

\begin{tabular}{|c|c|c|c|c|c|c|c|}
\hline \multirow{3}{*}{ Região } & \multicolumn{7}{|c|}{ Vencimentos / Anos } \\
\hline & \multicolumn{4}{|c|}{ março } & \multicolumn{3}{|c|}{ maio } \\
\hline & 2001 & 2002 & 2003 & 2004 & 2001 & 2002 & 2003 \\
\hline Balsas - MA & 0,726 & 0,091 & 0,021 & 0,167 & 0,291 & 0,687 & 0,386 \\
\hline Barreiras - BA & 0,836 & 0,028 & 0,273 & 0,094 & 0,780 & 0,042 & 0,201 \\
\hline Campo Mourão - PR & 0,743 & 0,019 & 0,059 & 0,390 & 0,840 & 0,284 & 0,009 \\
\hline Candido Mota - SP & 0,759 & 0,012 & 0,004 & 0,106 & 0,882 & 0,298 & 0,002 \\
\hline Cascavel - PR & 0,722 & 0,026 & 0,055 & 0,371 & 0,861 & 0,318 & 0,016 \\
\hline Chapecó - SC & 0,428 & 0,001 & 0,005 & 0,173 & 0,831 & 0,387 & 0,201 \\
\hline Cuiabá - MT & 0,715 & 0,000 & 0,001 & 0,173 & 0,819 & 0,039 & 0,000 \\
\hline Dourados - MS & 0,777 & 0,031 & 0,000 & 0,012 & 0,877 & 0,012 & 0,130 \\
\hline Maringá - PR & 0,738 & 0,015 & 0,137 & 0,333 & 0,871 & 0,279 & 0,022 \\
\hline Orlândia - SP & 0,699 & 0,020 & 0,000 & 0,267 & 0,740 & 0,359 & 0,000 \\
\hline Passo Fundo - RS & 0,401 & 0,004 & 0,000 & 0,008 & 0,814 & 0,684 & 0,059 \\
\hline Ponta Grossa - PR & 0,707 & 0,011 & 0,296 & 0,023 & 0,898 & 0,295 & 0,561 \\
\hline Rio Verde- GO & 0,604 & 0,000 & 0,052 & 0,150 & 0,816 & 0,078 & 0,029 \\
\hline Rondonópolis - MT & 0,748 & 0,012 & 0,000 & 0,140 & 0,868 & 0,003 & 0,000 \\
\hline Sorriso - MT & 0,710 & 0,029 & 0,000 & 0,120 & 0,871 & 0,029 & 0,109 \\
\hline Uberlândia - MG & 0,784 & 0,012 & 0,041 & 0,001 & 0,824 & 0,000 & 0,107 \\
\hline
\end{tabular}

Fonte: Resultados da pesquisa. 
Quadro 3- Efetividade para os contratos com vencimentos em julho e agosto

\begin{tabular}{lcccccc}
\hline & \multicolumn{5}{c}{ Vencimentos / Anos } \\
\cline { 2 - 7 } \multicolumn{1}{c}{ Região } & $\mathbf{2 0 0 1}$ & $\mathbf{2 0 0 2}$ & $\mathbf{2 0 0 3}$ & $\mathbf{2 0 0 1}$ & $\mathbf{2 0 0 2}$ & $\mathbf{2 0 0 3}$ \\
\cline { 2 - 7 } Balsas - MA & - & 0,900 & 0,343 & - & 0,835 & 0,455 \\
Barreiras - BA & 0,797 & 0,811 & 0,023 & 0,943 & 0,698 & 0,080 \\
Campo Mourão - PR & 0,832 & 0,788 & 0,806 & 0,944 & 0,588 & 0,820 \\
Candido Mota - SP & - & 0,806 & 0,793 & - & 0,710 & 0,692 \\
Cascavel - PR & 0,815 & 0,780 & 0,814 & 0,940 & 0,531 & 0,807 \\
Chapecó - SC & 0,583 & 0,759 & 0,418 & 0,904 & 0,592 & 0,500 \\
Cuiabá - MT & 0,736 & 0,821 & 0,391 & 0,916 & 0,782 & 0,004 \\
Dourados - MS & 0,863 & 0,632 & 0,796 & 0,928 & 0,626 & 0,624 \\
Maringá - PR & 0,817 & 0,723 & 0,490 & 0,926 & 0,548 & 0,705 \\
Orlândia - SP & 0,057 & 0,706 & 0,648 & 0,745 & 0,698 & 0,305 \\
Passo Fundo - RS & 0,572 & 0,771 & 0,445 & 0,938 & 0,670 & 0,716 \\
Ponta Grossa - PR & 0,872 & 0,545 & 0,782 & 0,974 & 0,459 & 0,760 \\
Rio Verde- GO & 0,235 & 0,806 & 0,807 & 0,834 & 0,619 & 0,552 \\
Rondonópolis - MT & 0,542 & 0,875 & 0,341 & 0,885 & 0,786 & 0,001 \\
Sorriso - MT & - & 0,859 & 0,277 & - & 0,774 & 0,000 \\
Uberlândia - MG & 0,000 & 0,739 & 0,626 & 0,668 & 0,674 & 0,397 \\
\hline
\end{tabular}

Fonte: Resultados da pesquisa. 
Quadro 4 - Efetividade para os contratos com vencimento em setembro e novembro

\begin{tabular}{lcccccc}
\hline & \multicolumn{5}{c}{ Vencimentos / Anos } \\
\cline { 2 - 7 } \multicolumn{1}{c}{ Região } & \multicolumn{5}{c}{ setembro } & \multicolumn{3}{c}{ novembro } \\
\cline { 2 - 7 } & $\mathbf{2 0 0 1}$ & $\mathbf{2 0 0 2}$ & $\mathbf{2 0 0 3}$ & $\mathbf{2 0 0 1}$ & $\mathbf{2 0 0 2}$ & $\mathbf{2 0 0 3}$ \\
\hline Balsas - MA & - & 0,695 & 0,561 & 0,0612 & 0,0844 & 0,9083 \\
Barreiras - BA & 0,796 & 0,685 & 0,131 & 0,2646 & 0,4691 & 0,9648 \\
Campo Mourão - PR & 0,695 & 0,531 & 0,796 & 0,3639 & 0,4500 & 0,9661 \\
Candido Mota - SP & - & 0,696 & 0,774 & - & 0,5871 & 0,9695 \\
Cascavel - PR & 0,686 & 0,476 & 0,779 & 0,333 & 0,435 & 0,966 \\
Chapecó - SC & 0,600 & 0,482 & 0,475 & 0,293 & 0,266 & 0,949 \\
Cuiabá - MT & 0,777 & 0,719 & 0,046 & 0,187 & 0,431 & 0,963 \\
Dourados - MS & 0,669 & 0,635 & 0,776 & 0,328 & 0,598 & 0,977 \\
Maringá - PR & 0,698 & 0,521 & 0,728 & 0,204 & 0,496 & 0,961 \\
Orlândia - SP & 0,601 & 0,511 & 0,363 & 0,269 & 0,202 & 0,925 \\
Passo Fundo - RS & 0,687 & 0,602 & 0,679 & 0,291 & 0,456 & 0,961 \\
Ponta Grossa - PR & 0,749 & 0,423 & 0,738 & 0,001 & 0,418 & 0,935 \\
Rio Verde- GO & 0,716 & 0,431 & 0,621 & 0,384 & 0,264 & 0,972 \\
Rondonópolis - MT & 0,816 & 0,709 & 0,036 & 0,373 & 0,340 & 0,981 \\
Sorriso - MT & - & 0,695 & 0,037 & - & 0,4405 & 0,9694 \\
Uberlândia - MG & 0,725 & 0,464 & 0,525 & 0,0074 & 0,2710 & 0,9537 \\
\hline Fone: Resuny
\end{tabular}

Fonte: Resultados da pesquisa. 
Quadro 5 - Média da efetividade para cada um dos vencimentos

\begin{tabular}{|c|c|c|c|c|c|c|c|c|}
\hline \multirow{2}{*}{ Região } & \multicolumn{7}{|c|}{ Vencimentos } & \multirow[t]{2}{*}{ médi: } \\
\hline & jan & $\operatorname{mar}$ & mai & jul & ago & set & nov & \\
\hline Balsas & 0,594 & 0,251 & 0,455 & 0,622 & 0,645 & 0,628 & 0,351 & 0,507 \\
\hline Barreiras & 0,382 & 0,308 & 0,341 & 0,544 & 0,574 & 0,537 & 0,566 & 0,464 \\
\hline Campo Mourão & 0,521 & 0,303 & 0,378 & 0,809 & 0,784 & 0,674 & 0,593 & 0,580 \\
\hline Candido Mota & 0,483 & 0,220 & 0,394 & 0,799 & 0,701 & 0,735 & 0,778 & 0,587 \\
\hline Cascavel & 0,507 & 0,294 & 0,398 & 0,803 & 0,759 & 0,647 & 0,578 & 0,569 \\
\hline Chapecó & 0,455 & 0,152 & 0,473 & 0,587 & 0,665 & 0,519 & 0,503 & 0,479 \\
\hline Cuiabá & 0,302 & 0,222 & 0,286 & 0,649 & 0,567 & 0,514 & 0,527 & 0,438 \\
\hline Dourados & 0,384 & 0,205 & 0,340 & 0,764 & 0,726 & 0,694 & 0,634 & 0,535 \\
\hline Maringá & 0,526 & 0,306 & 0,391 & 0,677 & 0,726 & 0,649 & 0,554 & 0,547 \\
\hline Orlândia & 0,518 & 0,247 & 0,366 & 0,470 & 0,583 & 0,492 & 0,465 & 0,449 \\
\hline Passo Fundo & 0,444 & 0,103 & 0,519 & 0,596 & 0,774 & 0,656 & 0,569 & 0,523 \\
\hline Ponta Grossa & 0,489 & 0,259 & 0,585 & 0,733 & 0,731 & 0,637 & 0,451 & 0,555 \\
\hline Rio Verde & 0,494 & 0,201 & 0,307 & 0,616 & 0,668 & 0,590 & 0,540 & 0,488 \\
\hline Rondonópolis & 0,272 & 0,225 & 0,290 & 0,586 & 0,557 & 0,521 & 0,565 & 0,431 \\
\hline Sorriso & 0,318 & 0,215 & 0,336 & 0,568 & 0,387 & 0,366 & 0,705 & 0,414 \\
\hline Uberlândia & 0,542 & 0,209 & 0,311 & 0,455 & 0,580 & 0,572 & 0,411 & 0,440 \\
\hline Média & 0,452 & 0,233 & 0,386 & 0,642 & 0,652 & 0,589 & 0,549 & \\
\hline Média & \multicolumn{4}{|c|}{ Primeiro semestre $=0,356$} & \multicolumn{3}{|c|}{ Segundo semestre $=\mathbf{0 , 6 0}$} & \\
\hline
\end{tabular}

Fonte: Resultados da pesquisa. 
REVISTA DE ECONOMIA E AGRONEGÓCIO, VOL.2, $N^{o} 4$ 